\title{
Aquaporinas: de canais de água a transportadores multifuncionais em plantas
}

\author{
MARÍLIA GASPAR ${ }^{1}$
}

(recebido: 09 de novembro de 2011; aceito: 08 de dezembro de 2011)

\begin{abstract}
Aquaporins: from water channels to multifunctional transporters in plants). From the functional identification of the first plant aquaporin, in 1993, up to today, a lot of information about the structure, location and function of different members of this multigene family of membrane proteins was provided by the scientific community. Initially regarded as "simple water channels", the aquaporins have been shown to transport gases and small neutral solutes such as glycerol, urea and silicon, transforming the concept of transmembrane transport. Due to the redundancy of aquaporin genes and their distribution in all organs and plant tissues, these proteins have been considered essential in maintaining vital functions in plants such as water and nutrient uptake in roots, seed germination, photosynthesis, transpiration and reproduction. This work presents a review on molecular and functional characterization of aquaporins and their relevance for plant development and in response to environmental stresses. Despite advances in research on plant aquaporins, there are few studies with native species from tropical regions and therefore there is a vast field of research to be explored, given the differences in water availability, the occurrence of various environmental stresses in tropical biomes, and the mechanisms employed by plants of these regions to be adapted to the wide variety of environmental conditions.
\end{abstract}

Key words - major intrinsic protein (MIP), solute transport, stress response, water balance

RESUMO - (Aquaporinas: de canais de água a transportadores multifuncionais em plantas). Da identificação funcional da primeira aquaporina de plantas, em 1993, aos dias de hoje, uma grande quantidade de informações sobre a estrutura, a localização e a função dos diferentes membros desta família multigênica de proteínas de membrana foi disponibilizada pela comunidade científica. Inicialmente consideradas como "simples canais de água", as aquaporinas se mostraram capazes de transportar gases e pequenos solutos neutros, como glicerol, uréia e silício, revolucionando o conceito de transporte transmembrana. Devido à redundância dos genes de aquaporinas e à sua distribuição em todos os órgãos e tecidos vegetais, essas proteínas têm sido consideradas essenciais na manutenção de funções vitais, como absorção de água e nutrientes em raízes, germinação de sementes, fotossíntese, transpiração e reprodução. O presente trabalho faz uma revisão sobre a caracterização funcional e molecular das aquaporinas e sua importância no desenvolvimento da planta e na resposta a estresses ambientais. Apesar dos avanços nas pesquisas com aquaporinas de plantas, existem poucos estudos com espécies nativas de regiões tropicais havendo, portanto, vasto campo de pesquisa a ser explorado, tendo em vista as diferenças na disponibilidade de água, a ocorrência de estresses ambientais diversos nos biomas tropicais e os mecanismos empregados pelas plantas dessas regiões para se adaptar à grande variedade de condições ambientais.

Palavras-chave - balanço hídrico, proteínas integrais de membrana (MIP), resposta a estresses, transporte de solutos

\section{Introdução}

Durante muito tempo, considerou-se que o transporte de água ocorria por simples difusão entre as moléculas lipídicas das membranas celulares, sem intervenção de um sistema de transporte específico. No entanto, as elevadas taxas de permeabilidade hídrica de algumas membranas, como as dos glóbulos vermelhos e células do epitélio renal, não poderiam ser explicadas somente por difusão (Macey 1984). Da mesma forma, diversos eventos, como alongamento celular, abertura

1. Instituto de Botânica, Núcleo de Pesquisas em Fisiologia e Bioquímica, Caixa Postal 68041, 04045-972 São Paulo, SP, Brasil. gaspar.marilia@gmail.com e fechamento dos estômatos, que demandam uma rápida translocação de água através das membranas vegetais, sugeriam a presença de canais específicos para esta função. A inibição do transporte de água na presença de íons mercúrio $\left(\mathrm{Hg}^{2+}\right)$, capazes de oxidar os grupos sulfidrila das proteínas, era um argumento extra a favor da existência de um sistema protéico de transporte (Macey 1984). Entretanto, até meados dos anos 80 nenhum grupo de pesquisa tinha sido capaz de identificar uma proteína canal de água e o tema era, ainda, bastante controverso.

Em 1991, Preston \& Agre isolaram a partir de glóbulos vermelhos uma proteína de massa molecular $28 \mathrm{kDa}$, denominada CHIP28 (Channel Forming Intrinsic Protein of $28 \mathrm{kDa})$. A função de canal de água dessa 
proteína foi comprovada no ano seguinte, através da expressão em sistema heterólogo de ovócitos de Xenopus laevis (Preston et al. 1992). Esses autores demonstraram que a permeabilidade dos ovócitos que expressavam CHIP28 era cinco a oito vezes maior que aquela dos ovócitos controle e podia ser inibida de maneira reversível por $\mathrm{HgCl}_{2}$. Esses resultados foram confirmados pela reconstituição de canais de água funcionais em lipossomos contendo a proteína CHIP28 purificada (Van Hoek \& Verkman 1992, Zeidel et al. 1992). Em 2003, o Dr. Peter Agre foi agraciado com o prêmio Nobel de Química, como recompensa pela descoberta de proteínas que revolucionaram o conceito de transporte de água através das células. Devido à sua função, essas proteínas foram denominadas aquaporinas (AQPs). No entanto, sabe-se atualmente que as aquaporinas são capazes de transportar outras moléculas além da água, conforme será discutido adiante.

Desde sua descoberta, membros da família das proteínas canais de água, denominadas de MIPs (Major Intrinsic Proteins), foram encontrados em praticamente todos os organismos vivos. A abundância dessas proteínas em plantas foi sem dúvida uma das principais razões que permitiram sua identificação por técnicas bioquímicas e moleculares, antes que sua função fosse conhecida. A primeira MIP de plantas, identificada em feijão, representa aproximadamente $2 \%$ do total de proteínas extraídas do cotilédone desta espécie (Johnson et al. 1989). A função de canal de água foi demonstrada pela primeira vez em plantas para uma proteína isolada de Arabidopsis thaliana (L.) Heynh. (Maurel et al. 1993), abrindo novas perspectivas quanto à compreensão dos mecanismos que regulam o fluxo de água transmembrana em vegetais.

\section{Estrutura molecular das aquaporinas e sua relação com a especificidade a diferentes substratos}

A massa molecular média das aquaporinas, deduzida a partir das sequências de nucleotídeos, varia entre $26 \mathrm{e}$ $34 \mathrm{kDa}$. Essas proteínas possuem uma estrutura bastante conservada, com seis hélices transmembrana, três alças extracelulares e duas intracelulares, e domínios N- e Cterminal citoplasmáticos. A sequência dessas proteínas mostra duas regiões homólogas em orientação inversa, cada uma constituída de três hélices transmembrana. Segundo Reizer et al. (1993), essa estrutura poderia ser resultante da duplicação de um gene ancestral procarioto, ocorrida há 2,5 bilhões de anos, antes do aparecimento dos eucariotos. Após essa duplicação, teria ocorrido a diferenciação das regiões N- e C-terminal da proteína, que diferenciam as subfamílias conhecidas atualmente (Reizer et al. 1993). Dois motivos conservados de aminoácidos, asparagina-prolina-alanina (NPA), estão localizados na primeira alça citoplasmática e na terceira alça extracelular, que se dobram e se inserem no centro da membrana, contribuindo para a formação do canal. Apesar da grande permeabilidade à água - AQP1 de mamíferos permite o transporte de $3 \times 10^{9}$ moléculas de água por monômero por segundo (Zeidel et al. 1992) - as aquaporinas bloqueiam o transporte de prótons, através da formação de pontes de hidrogênio entre as moléculas de água e os resíduos de asparagina dos motivos NPA, impossibilitando a formação de pontes de hidrogênio entre as moléculas de água dentro do canal (Murata et al. 2000).

$\mathrm{O}$ diâmetro do poro de uma aquaporina clássica, como AQP1 de mamíferos, é de $3 \AA$, diâmetro próximo ao de uma molécula de água $(2,8 \AA)$, sendo que este valor pode variar conforme a especificidade de transporte da proteína (Murata et al. 2000). Além do diâmetro do poro, diferenças de conformação entre aquaporinas e transportadores de glicerol (aquagliceroporinas) foram identificadas nas alças extracelulares A, C e E (Gonen \& Walz 2006). Segundo Wallace \& Roberts (2004), a estrutura da proteína, juntamente com o motivo aminoácido aromático/arginina ( $\mathrm{ar} / \mathrm{R})$, localizado na região de constrição do poro, determina a especificidade do substrato nos diferentes canais. Análises de alinhamento de sequências e modelagem molecular sugerem grande diversidade estrutural nas sequências envolvidas na formação do canal, permitindo separar as aquaporinas de Arabidopsis em oito grupos ar/R distintos com diferentes propriedades funcionais (Wallace \& Roberts 2004). Segundo os autores, alguns grupos, como as proteínas intrínsecas de membrana plasmática (PIPs) de plantas, que possuem alta homologia na região do poro, atuariam como aquaporinas ou aquagliceroporinas, enquanto grupos com sequências ar/R divergentes teriam funções de transporte distintas. No entanto, vale ressaltar que o transporte através das aquaporinas é regulado por outros fatores, como fosforilação e $\mathrm{pH}$, e o efeito destes na estrutura do poro não foi, ainda, determinado.

Além de água e glicerol, o transporte de várias moléculas, como dióxido de carbono $\left(\mathrm{CO}_{2}\right)$, óxido nítrico (NO), peróxido de hidrogênio $\left(\mathrm{H}_{2} \mathrm{O}_{2}\right)$, amônia $\left(\mathrm{NH}_{3}\right)$, arsenito $\left(\mathrm{As}(\mathrm{OH})_{3}\right)$, ácido bórico $\left(\mathrm{B}(\mathrm{OH})_{3}\right)$ e uréia já foi demonstrado para diversas aquaporinas vegetais. Ao comparar as características estruturais de AQPs de diferentes organismos, Wu \& Beitz (2007) sugeriram que todas as aquaporinas, independente de sua sequência de aminoácidos, são permeáveis aos gases $\mathrm{NO}$ e $\mathrm{CO}_{2}$, 
moléculas pequenas capazes de atravessar os poros mais estreitos. No entanto, moléculas maiores como os ácidos salicílico e lático ou a uréia, só podem ser transportados por isoformas específicas (Wu \& Beitz 2007). Geralmente, as aquaporinas estão inseridas na membrana em arranjos tetraméricos, sendo cada monômero uma unidade funcional independente (Groot \& Grubmuller 2001). Essa associação em tetrâmeros poderia criar um quinto poro central, insensível aos inibidores comumente testados, representando uma rota alternativa de transporte pelas aquaporinas, conforme sugerido por diversos autores (Hub \& Groot 2006, Bertl \& Kaldenhoff 2007, Wang et al. 2007).

\section{Por que são necessários tantos genes de aquaporinas em plantas?}

As aquaporinas são particularmente abundantes em plantas superiores. Até o momento, 13 homólogos foram descritos em humanos (Magni et al. 2006). Os genomas de plantas superiores, como arroz, milho e Arabidopsis, possuem mais de 30 homólogos identificados (Chaumont et al. 2001, Johanson et al. 2001, Sakurai et al. 2005), sendo que em Populus e algodão foram identificados 55 e 63 genes de aquaporinas, respectivamente (Gupta et al. 2009, Park et al. 2010). Com base na similaridade da sequência de nucleotídeos, as aquaporinas vegetais foram classificadas inicialmente em quatro diferentes subfamílias, denominadas PIPs (Plasma membrane Intrinsic Proteins), TIPs (Tonoplast Intrinsic Proteins), NIPs (Nodulin26-like Intrinsic Proteins) e SIPs (Small basic Intrinsic Proteins) (Johanson et al. 2001) sendo esta divisão diretamente associada à localização subcelular específica dos membros de algumas subfamílias (membrana plasmática e tonoplasto). Recentemente, uma quinta subfamília, denominada XIPs (X Intrinsic Proteins), foi identificada em liquens e algumas espécies de plantas superiores (Danielson \& Johanson 2008, Liénard et al. 2008).

Segundo Forrest \& Bhave (2007), a natureza séssil das plantas e a ausência de um sistema circulatório são fatores que explicariam, ao menos em parte, o fato da superfamília MIP ser mais diversa e complexa nesses organismos do que em animais. Segundo Wudick et al. (2009), essa grande variedade de aquaporinas em plantas poderia estar relacionada à seletividade aos diferentes substratos, aos diversos padrões de localização celular e tecidual, ao alto nível de compartimentalização das células vegetais e às diversas funções celulares que promovem o equilíbrio hídrico e osmótico entre os compartimentos.

\section{O papel das aquaporinas no crescimento e desenvolvimento em plantas}

Na reprodução sexuada em plantas, o movimento de água e solutos é altamente regulado, sugerindo a presença de aquaporinas nas estruturas reprodutivas. Em tabaco, genes de aquaporinas de membrana plasmática (PIP1 e PIP2) foram identificados durante o desenvolvimento da antera (Bots et al. 2005a), sendo que plantas de tabaco transgênicas com silenciamento do gene PIP2 apresentaram desidratação mais lenta e atraso na deiscência das anteras (Bots et al. 2005b). Em Arabidopsis, foram identificados dois genes de aquaporinas de tonoplasto, denominados TIP5;1 e TIP 1;3, com alta expressão nos grãos de pólen maduros e capazes de transportar água e uréia quando expressos em ovócitos de Xenopus (Soto et al. 2008). Mutantes desses genes possuem tubos polínicos mais curtos quando germinados em meio com baixas concentrações de nitrogênio, sugerindo que nestas condições estes genes são importantes para o alongamento do tubo polínico (Soto et al. 2008). Ainda em Arabidopsis, oito genes PIP foram detectados nos botões florais, sugerindo o envolvimento das aquaporinas no desenvolvimento floral (Quigley et al. 2002). Em tulipas, mudanças de temperatura associadas a alterações na atividade de aquaporina foram relacionadas à abertura e fechamento das pétalas (Azad et al. 2004), enquanto em rosas, a inibição da expansão celular em pétalas em função do tratamento com etileno foi diretamente correlacionada a uma diminuição no teor de água deste tecido e, concomitantemente, à diminuição de expressão do gene RhPIP2; 1 (Ma et al. 2008).

$\mathrm{O}$ desenvolvimento e a germinação de sementes representam outra etapa crucial do desenvolvimento vegetal, na qual a presença de aquaporinas pode regular o transporte de água requerido durante a embebição, o crescimento embrionário e a protrusão da radícula. No entanto, embora a primeira aquaporina identificada em plantas tenha sido isolada de sementes, ainda existem diversas lacunas sobre o papel das aquaporinas no desenvolvimento e germinação. Dois genes de aquaporinas isolados de sementes de canola (Brassica napus L.), BnPIP1 e BnTIP2, foram relacionados a etapas distintas do processo germinativo (Gao et al. 1999). BnPIP1 atuaria preferencialmente no transporte de água necessário para a ativação das enzimas e mobilização das reservas nos estágios iniciais da germinação, enquanto a expressão de BnTIP2 foi correlacionada ao alongamento celular associado à protrusão da radícula (Gao et al. 1999). Estudos 
realizados em sementes de ervilha demonstraram o envolvimento de aquaporinas no fluxo de água e solutos através da membrana das células parenquimáticas do tegumento, responsáveis pelo fornecimento de nutrientes para o desenvolvimento dos tecidos e para a síntese de compostos de reserva (Schuurmans et al. 2003). Além da função de transporte de água, uma aquaporina do tipo NIP, expressa especificamente no tegumento da semente, apresentou alta capacidade de transporte de glicerol quando testada em sistema heterólogo (Schuurmans et al. 2003). A expressão de genes de aquaporina associada à função de transporte de nutrientes também foi demonstrada durante o desenvolvimento de sementes de uma gimnosperma (Picea abies (L.) H. Karst.) (Hakman \& Oliviusson 2002). Uma análise mais ampla do perfil de expressão de diversas aquaporinas de Arabidopsis pela técnica de microarranjo permitiu identificar genes expressos nas sementes quiescentes e germinantes. Os resultados mostraram dois genes TIP3 e um TIP5 altamente expressos na semente quiescente e uma mudança nesse padrão durante a germinação, com expressão preferencial de genes das subfamílias TIP1 e TIP2. O acúmulo de transcritos do tipo PIP em sementes de Arabidopsis foi discreto, sendo observado um aumento de expressão somente durante a fase final de crescimento embrionário (Willigen et al. 2006). Em contraste ao observado em sementes de Arabidopsis, diversas isoformas PIP tiveram sua expressão modulada durante a germinação de sementes de arroz, com picos de acúmulo de transcritos nos embriões entre 36 e 72 horas após a embebição (Liu et al. 2007). A importância das PIPs na germinação de sementes de arroz foi confirmada por análise de plantas transgênicas antisenso para o gene $O_{S P I P 1 ; 3}$, que apresentaram taxas de germinação aproximadamente $30 \%$ menores do que as plantas controle, devido à diminuição da capacidade de absorção de água (Liu et al. 2007).

Ao ser absorvida do solo, a água percorre um trajeto radial até o centro da raiz e a seguir um trajeto axial ascendente nos vasos condutores do xilema. Devido à ausência de células, a contribuição das aquaporinas à via axial de transporte de água é insignificante. Já no trajeto radial, a contribuição das aquaporinas é fundamental na via denominada transcelular, na qual a água atravessa diversas camadas de células em série, passando obrigatoriamente pela membrana plasmática e, em alguns casos, pelo tonoplasto. Alternativamente, a água pode atravessar as membranas celulares através da via simplástica (pelos plasmodesmas), ou circular entre as células, por uma via denominada apoplástica (Steudle 2000). Devido à sua eficiência em bloquear os canais de água, o efeito inibitório do cloreto de mercúrio $\left(\mathrm{HgCl}_{2}\right)$ foi bastante utilizado como ferramenta para estimar a contribuição das aquaporinas ao transporte de água em raízes de diversas espécies vegetais, com níveis de inibição da condutividade hidráulica entre 32 e 90\% (revisto por Javot \& Maurel 2002). No entanto, o uso desse inibidor não permite determinar com precisão o papel das aquaporinas no transporte de água em raízes, tendo em vista a presença de aquaporinas insensíveis ao mercúrio (Daniels et al. 1994), a baixa penetração deste nos tecidos (Gaspar et al. 2001) e seus efeitos tóxicos e inespecíficos, devido à propriedade do $\mathrm{HgCl}_{2}$ de se ligar aos resíduos de Cys de quaisquer proteínas. Por essa razão, outras abordagens têm sido empregadas, como o uso de plantas transgênicas, confirmando o importante papel de algumas isoformas de aquaporinas em raízes. Estudos com Arabidopsis e tabaco antisenso para os genes $P I P 1$ e $P I P 2$ demonstraram a contribuição destas duas subfamílias de aquaporinas para o transporte de água em raízes, sobretudo em situação de déficit hídrico (Kaldenhoff et al. 1998, Siefritz et al. 2002). A função específica de um gene de aquaporina altamente expresso em raízes de Arabidopsis (PIP2;1) no equilíbrio osmótico da seiva do xilema foi demonstrada através da análise de mutantes de inserção de T-DNA (Javot et al. 2003). A super-expressão de PIP 2; 1 em arroz levou a um aumento de aproximadamente $150 \%$ na biomassa de raízes e na condutividade hidráulica. No entanto, o cultivo em $100 \mathrm{mM}$ de $\mathrm{NaCl}$ levou a uma diminuição do crescimento após duas semanas, sugerindo uma maior sensibilidade das plantas transgênicas ao estresse salino (Katsuhara et al. 2003).

Variações de condutividade hidráulica em raízes $\left(L p_{r}\right)$ têm sido associadas a alterações de expressão de genes de aquaporinas neste órgão. Variações diuturnas de $\mathrm{Lp}_{\mathrm{r}}$ são acompanhadas por variações no nível de transcritos de aquaporinas do tipo PIP em raízes de Lotus japonicus (Regel) K. Larsen, milho e Pisum sativum L. (Henzler et al. 1999, Lopez et al. 2003, Beaudette et al. 2007). A expressão dessas aquaporinas se mostrou dependente do tipo de raiz (primária ou secundária) (Beaudette et al. 2007) e do estágio de desenvolvimento das mesmas, sendo observado em geral um aumento de expressão na zona de alongamento celular e nas regiões mais maduras da raiz primária de milho, nas quais a presença de uma hipoderme e endoderme suberizadas dificultam o transporte de água (Hachez et al. 2006). Além de facilitar o transporte de água e solutos, as aquaporinas também poderiam atuar como sensores de pressão osmótica e de turgor, como observado em raízes de milho (Gaspar et al. 2001), tendo em vista que sua 
capacidade de transporte de água é compatível com a estrutura de um sensor (Hill et al. 2004).

Aquaporinas de raízes também são consideradas fundamentais no transporte de solutos e nutrientes. A capacidade das aquaporinas em transportar uréia foi primeiramente observada em células renais de animais (Ishibashi et al. 1994). Posteriormente, essa propriedade foi confirmada em plantas, com o isolamento de aquaporinas de membrana plasmática, (Otto \& Kaldenhoff 2000, Gaspar et al. 2003) e de tonoplasto (Gerbeau et al. 1999, Liu et al. 2003) capazes de transportar uréia. Essas proteínas são reguladas diferencialmente em raízes na presença de nitrogênio, sendo que em milho $Z m P I P 1 ; 5$ tem sua expressão induzida na presença de nitrato, enquanto três genes TIP tem sua expressão induzida em raízes de Arabidopsis em situação de déficit de nitrogênio (Gaspar et al. 2003, Liu et al. 2003). O gene AtNIP 5; 1, cuja capacidade de transporte de ácido bórico foi demonstrada em ovócitos de Xenopus, tem sua expressão induzida em resposta à deficiência de boro, sendo que plantas mutantes para este gene apresentam retardo no desenvolvimento radicular na ausência desse nutriente (Takano et al. 2006). Martínez-Ballesta et. al. (2008) sugeriram o papel regulador do ácido bórico em algumas isoformas de aquaporinas como um dos possíveis mecanismos de tolerância ao estresse salino em raízes de milho. O papel de uma aquaporina do tipo NIP no transporte de ácido lático foi evidenciado em raízes de Arabidopsis em situação de estresse anaeróbico (Choi \& Roberts 2007). Mutantes de arroz deficientes para o gene $l s 1$, que codifica uma NIP capaz de transportar silício, apresentam diminuição na capacidade de absorção desse mineral em raízes e, consequentemente, menor translocação de silício para a parte aérea (Ma et al. 2006).

Assim como em raízes, o fluxo radial de água em folhas, que é controlado pela evapotranspiração, implica no transporte de água através das membranas e, consequentemente, na presença de proteínas canais de água. Também em folhas, a expressão de diferentes aquaporinas obedece a um padrão de regulação temporal e espacial. Enquanto algumas isoformas são expressas em folhas jovens em expansão, outras são expressas preferencialmente em folhas completamente expandidas, sendo que as aquaporinas expressas nas folhas maduras estão provavelmente envolvidas em processos fisiológicos como carregamento do floema, perda de água do xilema, abertura e fechamento estomático, transporte de $\mathrm{CO}_{2}$ na fotossíntese e movimento foliar (Heinen et al. 2009).

Sarda et al. (1997) identificaram dois genes de aquaporina expressos em folhas de girassol, mais especificamente nas células-guarda dos estômatos, denominados SunTIP7 e SunTIP20. Esses autores demonstraram que a variação no nível de transcritos de SunTIP7 acompanhava as alterações de condutância estomática $\left(\mathrm{g}_{\mathrm{s}}\right)$ ao longo do dia e aumentava em plantas submetidas ao déficit hídrico, sugerindo o papel desta aquaporina na modulação da abertura e fechamento estomático (Sarda et al. 1997). Aquaporinas expressas em células-guarda foram identificadas em diversas espécies, dentre as quais Vicia faba L., Arabidopsis, milho e espinafre (Kaldenhoff et al. 1995, Sun et al. 2001, Fraysse et al. 2005, Hachez et al. 2008). A expressão de aquaporinas também foi detectada em células da epiderme/periderme e tricomas. Em cevada, uma aquaporina funcional, HvPIP1;6, é expressa especificamente na epiderme foliar, com maior expressão na zona de alongamento, sugerindo a atuação dessa proteína no transporte de água associado ao crescimento celular (Wei et al. 2007). Aquaporinas potencialmente envolvidas nos processos de crescimento e divisão celular são expressas nas células do primórdio foliar e nas células meristemáticas em divisão (Jones \& Mullet 1995, Yamada et al. 1997; Chaumont et al. 1998, Hachez et al. 2008). Além disso, aquaporinas estão envolvidas no movimento foliar, como evidenciado em Samanea saman (Jacq.) Merr. pelo isolamento de proteínas funcionais das células do pulvino, espessamento da base das folhas responsável pelo ajuste do posicionamento foliar em resposta a estímulos endógenos e ambientais (Moshelion et al. 2002). O padrão de expresão de $S s A Q P 2$ variou durante o ciclo circadiano, com os maiores níveis de transcritos no período da manhã, provavelmente devido à alta demanda de fluxo de água durante a abertura do pulvino (Moshelion et al. 2002). A contribuição de aquaporinas no ajuste osmótico celular associado ao movimento foliar foi, também, demonstrada em tabaco e Mimosa pudica L. (Siefritz et al. 2004, Temmei et al. 2005).

A presença frequente de aquaporinas nos tecidos dos feixes vasculares, conforme observado nas células parenquimáticas do xilema e nas células companheiras do floema de milho e tabaco, sugere a atuação dessas proteínas no efluxo de água dos vasos do xilema e no carregamento do floema (Heinen et al. 2008). Estudos com Vriesea gigantea Mart. ex Schult. f., uma bromélia epífita com presença de tanque, mostraram que a absorção de uréia do tanque foi fortemente inibida (78\%) pelo tratamento com $\mathrm{HgCl}_{2}$, sugerindo a participação de aquaporinas no transporte desse nutriente (Inselsbacher et al. 2007). Dois genes de aquaporina com alta identidade de sequência com um gene PIP e 
um TIP para os quais a função de transporte de uréia foi previamente demonstrada, foram isolados da base das folhas de $V$. gigantea e tiveram sua expressão induzida na presença desse composto nitrogenado (Cambuí, Mercier \& Gaspar, dados não publicados). Segundo essas mesmas autoras, a presença dessas isoformas na porção basal das folhas, que assume o papel fisiológico de raiz nessa espécie de bromélia, sugere a atuação das aquaporinas para maior eficiência na utilização dos recursos hídricos e nutricionais, que ocorrem de forma ocasional e temporária em seu ambiente natural.

Evidências indiretas de que as aquaporinas também poderiam modular a condutância das células do mesófilo foliar $\left(\mathrm{g}_{\mathrm{m}}\right)$ foram fornecidas por Terashima \& Ono (2002), após tratarem folhas de Vicia faba e Phaseolus vulgaris $\mathrm{L}$. com $\mathrm{HgCl}_{2}$. Além de diminuir em 70 a $80 \%$ a condutividade hidráulica foliar, o tratamento com $\mathrm{HgCl}_{2}$ inibiu a fotossíntese, sendo observada diminuição nas taxas de assimilação de $\mathrm{CO}_{2}$ e de transporte de elétrons. Devido à sua capacidade de transporte de $\mathrm{CO}_{2}$ em sistema heterólogo, a aquaporina NtAQP1 foi considerada potencial candidata à modular a condutância das células do mesófilo foliar (Uehlein et al. 2003). Esta hipótese foi confirmada posteriormente por análises de plantas transgênicas com expressão constitutiva ou ausente de $N t A Q P 1$, que apresentaram $20 \%$ de aumento e $13 \%$ de diminuição, respectivamente, nas taxas de assimilação fotossintética, quando comparadas aos respectivos controles (Flexas et al. 2006). Medidas de fluorescência da clorofila e discriminação isotópica de ${ }^{13} \mathrm{C}$ indicaram que as diferenças na fotossíntese se devem a alterações na condutância do mesófilo foliar ao $\mathrm{CO}_{2}$, que foi $30 \%$ menor nas plantas antisenso e $20 \%$ maior nas plantas com super-expressão de NtAQP1 (Flexas et al. 2006). A determinação da localização subcelular de NtAQP1 na membrana interna dos cloroplastos, além de demonstrar pela primeira vez a presença de aquaporinas na membrana de organelas, permitiu atribuir a essa proteína um importante papel fisiológico in vivo, o de facilitar o transporte de $\mathrm{CO}_{2}$ para seu sítio de fixação no estroma dos cloroplastos (Uehlein et al. 2008). Esses estudos, em conjunto, confirmam o importante papel das aquaporinas permeáveis ao $\mathrm{CO}_{2}$, ou " $\mathrm{CO}_{2}$ aquaporinas" como sugerido por alguns autores, na regulação da fotossíntese em plantas.

\section{Aquaporinas e resposta a estresses ambientais}

Embora as aquaporinas tenham um papel chave na regulação do transporte de água, resultados contrastantes têm sido observados em situação de estresse ambiental.
Como relatado acima, a condutividade hidráulica de raízes é regulada parcialmente por aquaporinas, mais especificamente por PIPs (Javot et al. 2003, Postaire et al. 2010). No entanto, não é possível encontrar uma resposta comum dessa classe de proteínas em raízes submetidas a uma situação de déficit hídrico. Resultados de nove estudos em que a expressão de genes $P I P$ foi analisada em condição de seca mostraram que, dos 37 genes PIP estudados, 15 tiveram sua expressão diminuída, 13 tiveram aumento de expressão e nove mantiveram seus níveis de transcritos inalterados, indicando que cada gene PIP deve ter uma função específica na resposta ao estresse (Aroca et al. 2011).

Da mesma forma, respostas diferenciais à seca foram observadas em plantas transgênicas com inibição ou indução de determinadas isoformas de PIP. Plantas antisenso de tabaco e Arabidopsis com silenciamento de genes PIP apresentaram queda na capacidade de recuperação após imposição de déficit hídrico (Martre et al. 2002, Siefritz et al. 2002), enquanto plantas de tabaco e arroz com aumento de expressão de aquaporinas PIP1 e $P I P 2$, respectivamente, se mostraram hipersensíveis aos estresses hídrico e salino (Aharon et al. 2003, Katsuhara et al. 2003). Com relação às aquaporinas de tonoplasto, comportamentos diferenciais das plantas transformadas também foram observados. Sade et al. (2009) demonstraram que a expressão constitutiva de TIP2;2 em plantas de tomate foi capaz de modular a transpiração em diferentes situações ambientais e manter as funções fisiológicas, crescimento e produtividade em níveis normais, mesmo em condições de estresse hídrico e salino. Contrariamente ao observado em tomate, plantas de Arabidopsis super-expressando uma TIP de soja se mostraram mais suscetíveis à desidratação (Wang et al. 2011). Segundo Hussain et al. (2011), existem atualmente interpretações divergentes dos resultados obtidos com plantas transgênicas. Para alguns autores, o aumento nos níveis de aquaporina melhora a capacidade das plantas em lidar com o estresse hídrico, enquanto outros acreditam que as plantas evitam perdas excessivas de água ao "desligar" as aquaporinas durante a desidratação.

Além da seca, diversas isoformas de aquaporinas são moduladas por estresse salino e osmótico, por frio e por fitormônios, com grande variedade de respostas, como observado para o déficit hídrico (Suga et al. 2002, Jang et al. 2004, Sakurai et al. 2005, Yu et al. 2006, Peng et al. 2007). Plantas de Arabidopsis transformadas com aquaporinas de Rhododendron catawbiense Michx., cuja expressão se mostrou inibida em folhas com o aumento da tolerância ao frio, foram menos tolerantes ao congelamento do que as plantas controle (Peng et 
al. 2008). Análises anatômicas revelaram aumento do tamanho e espessura das folhas, como consequência de um aumento no tamanho das células da camada paliçádica e do mesófilo esponjoso, indicando que essas plantas, devido ao maior volume celular, estariam mais propensas a sofrer danos mecânicos durante a contração celular observada no processo de congelamento (Peng et al. 2008).

No entanto, é importante ressaltar a complexidade dos mecanismos de resposta à seca e aos demais estresses, sendo que outros fatores, em conjunto com as aquaporinas, são responsáveis pela resposta de tolerância. Esse fato é bastante evidente em plantas de Eragrostis nindensis Ficalho \& Hiem, tolerantes à dessecação, cujas folhas apresentaram, durante o processo de desidratação, diversas modificações anatômicas, bioquímicas e funcionais, como o dobramento da parede celular de células epidérmicas e do mesófilo e a formação de inúmeros pequenos vacúolos acumuladores de metabólitos osmoreguladores (prolina, proteínas e sacarose), associados ao aumento da expressão de TIP 3; 1 nos vacúolos dos tecidos desidratados (Willigen et al. 2004).

Embora inúmeros grupos de pesquisa tenham se dedicado ao estudo das aquaporinas de plantas nos últimos 20 anos, e múltiplas funções dessa família de proteínas tenham sido desvendadas, ainda restam lacunas na compreensão de seu funcionamento e interação com o ambiente. Sobretudo se considerarmos que a grande maioria dos trabalhos foi realizada com plantas modelo e espécies temperadas de interesse comercial. Dessa forma, espécies de regiões tropicais, distribuídas em ambientes com diferentes situações de disponibilidade de água, ou com variação sazonal desse recurso, além de espécies com adaptações morfológicas e bioquímicas que promovem melhor utilização dos recursos hídricos e nutricionais, têm sido negligenciadas. Mecanismos reprodutivos peculiares e ciclos de vida longos, associados à dificuldade de regeneração e cultivo in vitro, dificultam a obtenção de plantas transgênicas e, consequentemente, análises funcionais em espécies nativas de ambientes tropicais. A disponibilização de bancos de dados genômicos de algumas espécies, associada ao advento de técnicas de sequenciamento em larga escala, deve compensar, em médio prazo, a escassez de dados moleculares sobre as aquaporinas de plantas tropicais.

Agradecimentos - À editora-chefe da Revista Brasileira de Botânica, Dra. Sônia Machado de Campos Dietrich, pelo convite para publicação do artigo; à Dra. Solange Cristina Mazzoni-Viveiros, membro do Corpo Editorial, pela revisão criteriosa do manuscrito; à Dra. Kelly Simões, pelas valiosas sugestões e auxílio na formatação do texto e às Dras. Camila Aguetoni Cambuí e Helenice Mercier, pela preciosa colaboração nas pesquisas com aquaporinas de bromélias. À Fundação de Amparo à Pesquisa do Estado de São Paulo (Fapesp) pelo auxílio financeiro (05/04139-7; 06/50549-5).

\section{Referências bibliográficas}

AHARON, R., SHAHAK, Y., WININGER, S., BENDOV, R., KAPULNIK, Y. \& GALILI, G. 2003. Overexpression of a plasma membrane aquaporin in transgenic tobacco improves plant vigor under favorable growth conditions but not under drought or salt stress. The Plant Cell 15:439-447.

AROCA, R., PORCEL, R. \& RUIZ-LOZANO, J.M. 2011. Regulation of root water uptake under abiotic stress conditions. Journal of Experimental Botany. First published online September 13, 2011 doi:10.1093/jxb/ err266 (acesso em 19/10/2011).

AZAD, A.K., SAWA, Y., ISHIKAWA, T. \& SHIBATA, H. 2004. Phosphorylation of plasma membrane aquaporin regulates temperature-dependent opening of tulip petals. Plant Cell Physiology 45:608-617.

BEAUDETTE, P.C., CHLUP, M., YEE, J. \& EMERY, R.J.N. 2007. Relationships of root conductivity and aquaporin gene expression in Pisum sativum: diurnal patterns and the response to $\mathrm{HgCl}_{2}$ and $\mathrm{ABA}$. Journal of Experimental Botany 58:1291-1300.

BERTL, A. \& KALDENHOFF, R. 2007. Function of a separate $\mathrm{NH}_{3}$-pore in aquaporin TIP2;2 from wheat. FEBS Letters 581:5413-5417.

BOTS, M., FERON, R., UEHLEIN, N., WETERINGS, K., KALDENHOFF, R. \& MARIANI, T. 2005a. PIP1 and PIP2 aquaporins are differentially expressed during tobacco anther and stigma development. Journal of Experimental Botany 56:113-121.

BOTS, M., VERGELDT, F., WOLTERS-ARTS, M., WETERINGS, K., VAN, A.S.H. \& MARIANI, C. 2005b. Aquaporins of the PIP2 class are required for efficient anther dehiscence in tobacco. Plant Physiology 137:1049-1056.

CHAUMONT, F., BARRIEU, F., HERMAN, E.M. \& CHRISPEELS, M.J. 1998. Characterization of a maize tonoplast aquaporin expressed in zones of cell division and elongation. Plant Physiology 117:1143-1152.

CHAUMONT, F., BARRIEU, F., WOJCIK, E., CHRISPEELS, M.J. \& JUNG, R. 2001. Aquaporins constitute a large and highly divergent protein family in maize. Plant Physiology 125:1206-1215.

CHOI, W.G. \& ROBERTS, D.M. 2007. Arabidopsis NIP2;1, a major intrinsic protein transporter of lactic acid induced by anoxic stress. Journal of Biological Chemistry 282:24209-24218. 
DANIELS, M.J., MIRKOV, T.E. \& CHRISPEELS, M.J. 1994. The plasma membrane of Arabidopsis thaliana contains a mercury-insensitive aquaporin that is a homolog of the tonoplast water channel protein TIP. Plant Physiology 106:1325-1333.

DANIELSON, J.A.H. \& JOHANSON, U. 2008. Unexpected complexity of the aquaporin gene family in the moss Physcomitrella patens. BMC Plant Biology 8:45.

FLEXAS, J., RIBAS-CARBO, M., HANSON, D.T., BOTA, J., OTTO, B., CIFRE, J., MCDOWELL, N., MEDRANO, H. \& KALDENHOFF, R. 2006. Tobacco aquaporin NtAQP1 is involved in mesophyll conductance to $\mathrm{CO}_{2}$ in vivo. The Plant Journal 48:427-439.

FORREST, K.L. \& BHAVE, M. 2007. Major intrinsic proteins (MIPs) in plants: A complex gene family with major impacts on plant phenotype. Functional \& Integrative Genomics 7:263-289.

FRAYSSE, L.C., WELLS, B., MCCANN, M.C. \& KJELLBOM, P. 2005. Specific plasma membrane aquaporins of the PIP1 subfamily are expressed in sieve elements and guard cells. Biology of the Cell 97: 519-534.

GAO, Y-P, YOUNG, L. BONHAM-SMITH, P. \& GUSTA L.V. 1999. Characterization and expression of plasma and tonoplast membrane aquaporins in primed seed of Brassica napus during germination under stress conditions. Plant Molecular Biology 40:635-644.

GASPAR, M., BOUSSER, A., SISSOËFF, I., ROCHE, O., HOARAU, J. \& MAHE A. 2003. Cloning and characterization of ZmPIP1-5b, an aquaporin transporting water and urea. Plant Science 165:21-31.

GASPAR, M., SISSOËFF, I., BOUSSER, A., ROCHE, O., MAHÉ, A. \& HOARAU, J. 2001. Transient variations of water induced by $\mathrm{HgCl}_{2}$ in excised roots of young maize plants: new data on the inhibition process. Australian Journal of Plant Physiology 28: 1175-1186.

GERBEAU, P., GÜCLÜ, J., RIPOCHE, P. \& MAUREL, C. 1999. Aquaporin Nt-TIPa can account for the high permeability of tobacco cell vacuolar membrane to small neutral solutes. Plant Journal 18:577-87.

GONEN, T. \& WALZ, T. 2006. The structure of aquaporins. Quarterly Reviews of Biophysics 39:361-396.

GROOT, B.L. \& GRUBMULLER, H. 2001. Water permeation across biological membranes: mechanism and dynamics of aquaporin-1 and GlpF. Science 294:2353-2357

GUPTA, A.B. \& SANKARARAMAKRISHNAN, R. 2009. Genome-wide analysis of major intrinsic proteins in the tree plant Populus trichocarpa: characterization of XIP subfamily of aquaporins from evolutionary perspective. BMC Plant Biology 9:134.

HACHEZ, C., HEINEN, R.B., DRAYE, X. \& CHAUMONT, F. 2008. The expression pattern of plasma membrane aquaporins in maize leaf highlights their role in hydraulic regulation. Plant Molecular Biology 68:337-353.
HACHEZ, C., MOSHELION, M., ZELAZNY, E., CAVEZ, D. \& CHAUMONT, F. 2006. Localization and quantification of plasma membrane aquaporin expression in maize primary root: a clue to understanding their role as cellular plumbers. Plant Molecular Biology 62: 305-323.

HAKMAN, I. \& OLIVIUSSON, P. 2002. High expression of putative aquaporin genes in cells with transporting and nutritive functions during seed development in Norway spruce (Picea abies). Journal of Experimental Botany 53:639-649.

HEINEN, R.B, YE, Q. \& CHAUMONT, F. 2009. Role of aquaporins in leaf physiology. Journal of Experimental Botany 60:2971-2985.

HENZLER, T., WATERHOUSE, R.N., SMYTH, A.J., CARVAJAL, M., COOKE, D.T., SCHAFFNER, A.R., STEUDLE, E. \& CLARKSON, D.T. 1999. Diurnal variations in hydraulic conductivity and root pressure can be correlated with the expression of putative aquaporins in the roots of Lotus japonicus. Planta 210:50-60.

HILL, A.E., SHACHAR, H.B. \& SHACHAR, H.Y. 2004. What are aquaporins for? Journal of Membrane Biology 197:1-32.

HUB, J.S. \& GROOT, B.L. 2006. Does $\mathrm{CO}_{2}$ permeate through Aquaporin-1? Biophysical Journal 91:842-848.

HUSSAIN, S.S., IQBAL, M.T., ARIF, M.A. \& AMJAD, M. 2011. Beyond osmolytes and transcription factors: drought tolerance in plants via protective proteins and aquaporins. Biologia Plantarum 55:401-413.

INSELSBACHER, E., CAMBUI, C.A., RICHTER, A., STANGE, C.F., MERCIER, H., \& WANEK W. 2007. Microbial activities and foliar uptake of nitrogen in the epiphytic bromeliad Vriesea gigantea. New Phytologist 175:311-320.

ISHIBASHI, K., SASAKI, S., FUSHIMI, K., UCHIDA, S., KUWAHARA, M., SAITO, H., FURUKAWA, T., NAKAJIMA, K., YAMAGUCHI, Y. \& GOJOBORI, T. 1994. Molecular cloning and expression of a member of the aquaporin family with permeability to glycerol and urea in addition to water expressed at the basolateral membrane of kidney collecting duct cells. Proceedings of the National Academy of Sciences USA 91:6269-6273.

JANG, J.Y., KIM, D.G., KIM, Y.O., KIM, J.S. \& KANG, H. 2004. An expression analysis of a gene family encoding plasma membrane aquaporins in response to abiotic stresses in Arabidopsis thaliana. Plant Molecular Biology 54:713-25.

JAVOT, H. \& MAUREL, C. 2002. The role of aquaporins in root water uptake. Annals of Botany 90:301-13

JAVOT, H., LAUVERGEAT, V., SANTONI, V., MARTINLAURENT, F., GÜÇLÜ, J., VINH, J., HEYES, J., FRANCK, K.I., SCHÄFFNER, A.R., BOUCHEZ, D. \& MAUREL, C. 2003. Role of a single aquaporin isoform in root water uptake. Plant Cell 15:509-22 
JOHANSON, U., KARLSSON, M., JOHANSSON, I., GUSTAVSSON, S., SJOVALL, S., FRAYSSE, L., WEIG, A.R. \& KJELLBOM, P. 2001. The complete set of genes encoding major intrinsic proteins in Arabidopsis provides a framework for a new nomenclature for major intrinsic proteins in plants. Plant Physiology 126:1358-1369.

JOHNSON, K.D., HERMAN, E.M. \& CHRISPEELS, M.J. 1989. An abundant, highly conserved tonoplast protein in seeds. Plant Physiology 91:1006-1013.

JONES, J.T. \& MULLET, J.E. 1995. Developmental expression of a turgor responsive gene that encodes an intrinsic membrane-protein. Plant Molecular Biology 28:983-996.

KALDENHOFF, R., GROTE, K., ZHU, J.-J., \& ZIMMERMANN, U. 1998. Significance of plasmalemma aquaporins for water-transport in Arabidopsis thaliana. Plant Journal 14:121-128.

KALDENHOFF, R., KOLLING, A., MEYERS, J., KARMANN, U., RUPPEL, G. \& RICHTER G. 1995. The blue light-responsive AthH2 gene of Arabidopsis thaliana is primarily expressed in expanding as well as in differentiating cells and encodes a putative channel protein of the plasmalemma. The Plant Journal 7:87-95.

KATSUHARA, M., KOSHIO, K., SHIBASAKA, M., HAYASHI, Y., HAYAKAWA, T. \& KASAMO, K. 2003. Over-expression of a barley aquaporin increased the shoot/root ratio and raised salt sensitivity in transgenic rice plants. Plant Cell Physiology 44:1378-1383.

KATSUHARA, M., KOSHIO, K., SHIBASAKA, M., HAYASHI, Y., HAYAKAWA, T. \& KASAMO, K. 2003. Over-expression of a barley aquaporin increased the shoot/root ratio and raised salt sensitivity in transgenic rice plants. Plant Cell Physiology 44:1378-1383.

LIÉNARD, D., DURAMBUR, G., KIEFER-MEYER, M.-C., NOGUÉ, F., MENU-BOUAOUICHE, L., CHARLOT, F., GOMORD, V. \& LASSALLES, J.-P. 2008. Water transport by aquaporins in the extant plant Physcomitrella patens. Plant Physiology 146:1207-1218.

LIU, H-Y., YU, X., CUI, D-Y., SUN, M-H., SUN, W-N., TANG, Z-C., KWAK, S-S. \& SU, W-A. 2007. The role of water channel proteins and nitric oxide signaling in rice seed germination. Cell Research 17:638-649.

LIU, L.-H., LUDEWIG, U., GASSERT, B., FROMMER, W.B. \& VON WIREN, N. 2003. Urea transport by nitrogenregulated tonoplast intrinsic proteins in Arabidopsis. Plant Physiology 133:1220-1228.

LOPEZ, F., BOUSSER, A., SISSOEFF, I., GASPAR, M., LACHAISE, B., HOARAU, J. \& MAHE, A. 2003. Diurnal regulation of water transport and aquaporin gene expression in maize roots: contribution of PIP2 proteins. Plant Cell Physiology 44:1384-1395.

MA, J.F., TAMAI, K., YAMAJI, N., MITANI, N., KONISHI, S., KATSUHARA, M., ISHIGURO, M., MURATA, Y. \& YANO, M. 2006. A silicon transporter in rice. Nature 440:688-691.
MA, N., XUE, J., LI, Y., LIU, X., DAI, F., JIA, W., LUO, Y. \& GAO, J. 2008. Rh-PIP2;1, a rose aquaporin gene, is involved in ethylene-regulated petal expansion. Plant Physiology 148:894-907.

MACEY, R.I. 1984. Transport of water and urea in red blood cells. American Journal of Physiology 246:195-203.

MAGNI, F., SARTO, C., TICOZZI, D., SOLDI, M., BOSSO, N., MOCARELLI, P. \& KIENLE, M.G. 2006. Proteomic knowledge of human aquaporins. Proteomics 6:5637-5649.

MARTÍNEZ-BALLESTA, M.C., BASTÍAS, E., SCHÄFFNER, A., ZHU, C., GONZALEZ-MORO, B., GONZALEZ-MURUA, C. \& CARVAJAL, M. 2008. Boric acid and salinity on maize roots. Response of aquaporins ZmPIP1 and ZmPIP2 andATPase in relation to water and nutrient uptake. Physiologia Plantarum 132:479-490.

MARTRE, P., MORILLON, R., BARRIEU, F., NORTH, G.B., NOBEL, P.S. \& CHRISPEELS, M.J. 2002. Plasma membrane aquaporins play a significant role during recovery from water deficit. Plant Physiology 130:2101-2110.

MAUREL, C., REIZER, J., SCHROEDER, J.I. \& CHRISPEELS, M.J. 1993. The vacuolar membrane protein $\gamma$-TIP creates water specific channels in Xenopus oocytes. EMBO Journal 12:2241-2247.

MOSHELION, M., BECKER, D., BIELA, A., UEHLEIN, N., HEDRICH, R., OTTO, B., LEVI, H., MORAN, N. \& KALDENHOFF, R. 2002. Plasma membrane aquaporins in the motor cells of Samanea saman: diurnal and circadian regulation. The Plant Cell 14: 727-739.

MURATA, K., MITSUOKA, K., HIRAI, T., WALZ, T., AGRE, P., HEYMANN, J.B., ENGEL, A. \& FUJIYOSHI, Y. 2000. Structural determinants of water permeation through aquaporin-1. Nature 407:599-605.

OTTO, B. \& KALDENHOFF, R. 2000. Cell-specific expression of the mercury-insensitive plasmamembrane aquaporin NtAQP1 from Nicotiana tabacum. Planta 211:167-172.

PARK, W., SCHEFFLER, B.E., BAUER, P.J. \& CAMPBELL, B.T. 2010. Identification of the family of aquaporin genes and their expression in upland cotton (Gossypium hirsutum L.). BMC Plant Biology 10:142.

PENG, Y.H., ARORA, R., LI, G., WANG, X. \& FESSEHAIE, A. 2008. Rhododendron catawbiense plasma membrane intrinsic proteins are aquaporins, and their overexpression compromises constitutive freezing tolerance and cold acclimation ability of transgenic Arabidopsis plants. Plant, Cell and Environment 31:1275-1289.

PENG, Y.H., LIN, W.L., CAI, W.M. \& ARORA, R. 2007. Overexpression of a Panax ginseng tonoplast aquaporin alters sat tolerance, drought tolerance and cold acclimation ability in transgenic Arabidopsis plants. Planta 226:729-740. 
POSTAIRE, O., TOURNAIRE-ROUX, C., GRONDIN, A., BOURSIAC, Y., MORILLON, R., SHÄFFNER, A.R. \& MAUREL, C. 2010. A PIP1 aquaporin contributes to hydrostatic pressure-induced water transport in both the root and rosette of Arabidopsis. Plant Physiology 152:1418-1430.

PRESTON, G.M. \& AGRE, P. 1991. Isolation of the cDNA for erythrocyte integral membrane protein of 28 kilodaltons: member of an ancient channel family. Proceedings of the National Academy of Sciences of the United States of America 88:11110-11114.

PRESTON, G.M., CAROLL, T.P., GUGGINO, W.B. \& AGRE, P. 1992. Appearance of water channels in Xenopus oocytes expressing red cell CHIP28 protein. Science 256:385-387.

QUIGLEY, F., ROSENBERG, J.M., SHACHAR-HILL, Y. \& BOHNERT, H.J. 2002. From genome to function: the Arabidopsis aquaporins. Genome Biology 3:1-17.

REIZER, J., REIZER, A. \& SAIER JUNIOR, M.H. 1993. The MIP family of integral membrane channel proteins: sequence comparisons, evolutionary relationships, reconstructed pathway of evolution, and proposed functional differentiation of the two repeated halves of the proteins. Critical Reviews in Biochemistry and Molecular Biology 28:235-257.

SADE, N., VINOCUR, B.J., DIBER, A., SHATIL, A., NISSAN, H., WALLACH, R., KARCHI, H. \& MOSHELION, M. 2009. Improving plant stress tolerance and yield production: is the tonoplast aquaporin SITIP2;2 a key to isohydric to anisohydric conversion. New Phytologist 181:651-661.

SAKURAI, J., ISHIKAWA, F., YAMAGUCHI, T., UEMURA, M. \& MAESHIMA, M. 2005. Identification of 33 rice aquaporin genes and analysis of their expression and function. Plant and Cell Physiology 46:1568-1577.

SARDA, X., TOUSCH, D., FERRARE, K., LEGRAND, E., DUPUIS, J.M., CASSE-DELBART, F. \& LAMAZE, T. 1997. Two TIP-like genes encoding aquaporins are expressed in sunflower guard cells. Plant Journal 12:1103-1111.

SCHUURMANS, J.A., VAN DONGEN, J.T., RUTJENS, B.P., BOONMAN, A., PIETERSE, C.M. \& BORSTLAP, A.C. 2003. Members of the aquaporin family in the developing pea seed coat include representatives of the PIP, TIP, and NIP subfamilies. Plant Molecular Biology 53:633-645.

SIEFRITZ, F., OTTO, B., BIENERT, G.P., VAN DER KROL, A. \& KALDENHOFF, R. 2004. The plasma membrane aquaporin NtAQP1 is a key component of the leaf unfolding mechanism in tobacco. The Plant Journal 37:147-155.

SIEFRITZ, F., TYREE, M.T., LOVISOLO, C., SCHUBERT, A. \& KALDENHOFF, R. 2002. PIP1 plasma membrane aquaporins in tobacco: from cellular effects to function in plants. Plant Cell 14:869-876.
SOTO, G., ALLEVA, K., MAZZELLA, M.A., AMODEO, G. \& MUSCHIETTI, J.P. 2008. AtTIP1;3 and AtTIP5;1, the only highly expressed Arabidopsis pollen-specific aquaporins, transport water and urea. FEBS Letters 582:4077-4082.

STEUDLE, E. 2000. Water uptake by roots: effects of water déficit. Journal of Experimental Botany 51:1531-1542.

SUGA, S., KOMATSU, S. \& MAESHIMA, M. 2002. Aquaporin isoforms responsive to salt and water stresses and phytohormones in radish seedlings. Plant Cell Physiology 43:1229-1237.

SUN, M.H., XU, W., ZHU, Y.F., SU, W.A. \& TANG, Z.C. 2001. A simple method for in situ hybridization to RNA in guard cells of Vicia faba L.: the expression of aquaporins in guard cells. Plant Molecular Biology Reporter 19:129-135.

TAKANO, J., WADA, M., LUDEWIG, U., SCHAAF, G., VON WIR, E.N.N. \& FUJIWARA. T. 2006. The Arabidopsis major intrinsic protein NIP5;1 is essential for efficient boron uptake and plant development under boron limitation. Plant Cell 18:1498-509

TEMMEI, Y., UCHIDA, S., HOSHINO, D., KANZAWA, N., KUWAHARA, M., SASAKI, S. \& TSUCHIYA, T. 2005. Water channel activities of Mimosa pudica plasma membrane intrinsic proteins are regulated by direct interaction and phosphorylation. FEBS Letters 579:4417-4422.

TERASHIMA, I. \& ONO, K. 2002. Effects of $\mathrm{HgCl}_{2}$ on $\mathrm{CO}_{2}$ dependence of leaf photosynthesis: evidence indicating involvement of aquaporins in $\mathrm{CO}_{2}$ diffusion across the plasma membrane. Plant and Cell Physiology 43:70-78.

UEHLEIN, N., LOVISOLO, C., SIEFRITZ, F. \& KALDENHOFF, R. 2003. The tobacco aquaporin NtAQP1 is a membrane $\mathrm{CO} 2$ pore with physiological functions. Nature 425:734-737.

UEHLEIN, N., OTTO, B., HANSON, D.T., FISCHER, M., MCDOWELL, N. \& KALDENHOFF, R. 2008. Function of Nicotiana tabacum aquaporins as chloroplast gas pores challenges the concept of membrane $\mathrm{CO}_{2}$ permeability. The Plant Cell 20:648-657.

VAN HOEK, A.N. \& VERKMAN, A.S. 1992. Functional reconstitution of the isolated erythrocyte water channel CHIP28. Journal of Biological Chemistry 267: 18267-18269.

WALLACE, I.S. \& ROBERTS, D.M. 2004. Homology modeling of representative subfamilies of Arabidopsis major intrinsic proteins. Classification based on the aromatic/arginine selectivity filter. Plant Physiology 135:1059-1068.

WANG, X., LI, Y., JI, W., BAI, X., CAI, H., ZHU, D., SUN, X.-L., CHEN, L-J. \& ZHU, Y-M. 2011. A novel Glycine soja tonoplast intrinsic protein gene responds to abiotic stress and depresses salt and dehydration tolerance in transgenic Arabidopsis thaliana. Journal of Plant Physiology 161:1241-1248. 
WANG, Y., COHEN, J., BORON, W.F., SCHULTEN, K. \& TAJKHORSHID, E. 2007. Exploring gas permeability of cellular membranes and membrane channels with molecular dynamics. Journal of Structural Biology 157:534-544.

WEI, W., ALEXANDERSSON, E., GOLLDACK, D., MILLER, A.J., KJELLBOM, P.O. \& FRICKE, W. 2007. HvPIP 1;6, a barley (Hordeum vulgare L.) plasma membrane water channel particularly expressed in growing compared with non-growing leaf tissues. Plant and Cell Physiology 48:1132-1147.

WILLIGEN, C.V., PAMMENTER, N.W., MUNDREE, S.G. \& FARRANT, J.M. 2004. Mechanical stabilization of desiccated vegetative tissues of the resurrection grass Eragrostis nindensis: does a TIP 3;1 and/or compartmentalization of subcellular components and metabolites play a role? Journal of Experimental Botany 55:651-661.

WILLIGEN, C.V., POSTAIRE, O., TOURNAIRE-ROUX, C., BOURSIAC, Y. \& MAUREL, C. 2006. Expression and inhibition of aquaporins in germinating Arabidopsis Seeds. Plant Cell Physiology 47:1241-1250.
WU, B. \& BEITZ, E. 2007. Aquaporins with selectivity for unconventional permeants. Cellular and Molecular Life Sciences 64:2413-2421.

WUDICK, M.M., LUU, D.-T. \& MAUREL, C. 2009. A look inside: localization patterns and functions of intracellular plant aquaporins. New Phytologist 184: 289-302.

YAMADA, S., NELSON, D.E., LEY, E., MARQUEZ, S. \& BOHNERT, H.J. 1997. The expression of an aquaporin promoter from Mesembryanthemum crystallinum in tobacco. Plant and Cell Physiology 38: 1326-1332.

YU, X., PENG, Y.H., ZHANG, M.H., SHAO, Y.J., SU, W.A. \& TANG, Z.C. 2006. Water relations and expression analysis of plasma membrane intrinsic proteins in sensitive and tolerant rice during chiling and recovery. Cell Research 16:599-608.

ZEIDEL, M.L., AMBUDKAR, S.V., SMITH, B.L. \& AGRE, P. 1992. Reconstitution of functional water channels in liposomes containing purified red cell CHIP28 protein. Biochemistry 31:7436-7440. 